\title{
Quantitative evaluation of the therapeutic effect of fermented soybean products containing a high concentration of GABA on phthalic anhydride-induced atopic dermatitis in IL-4/Luc/CNS-1 Tg mice
}

\author{
YOUNG JU LEE ${ }^{1}$, JI EUN KIM ${ }^{1}$, MOON HWA KWAK ${ }^{1}$, JUN GO ${ }^{1}$, \\ DONG SEOB KIM ${ }^{2}$, HONG JOO SON ${ }^{3}$ and DAE YOUN HWANG ${ }^{1}$ \\ Departments of ${ }^{1}$ Biomaterials Science, ${ }^{2}$ Food Science and Technology, ${ }^{3}$ Life Science and Environment Biochemistry, \\ College of Natural Resources and Life Science/Life and Industry Convergence Research Institute, \\ Pusan National University, Gyeongsangnam-do 627-706, Republic of Korea
}

Received December 27, 2013; Accepted February 26, 2014

DOI: $10.3892 /$ ijmm.2014.1685

\begin{abstract}
Cheonggukjang(CKJ) isafermented soybean product that exhibits diverse biological and pharmacological activities, including anti-obesity, anti-diabetic, and anti-inflammatory effects on human chronic diseases. In this study, the effects of the aqueous extract of CKJ containing a high concentration of GABA on atopic dermatitis (AD) were quantified using the luciferase reporter system in IL-4/Luc/CNS-1 transgenic (Tg) mice. Alterations of the luciferase signal and phenotypes of AD were quantified in the IL-4/Luc/CNS-1 Tg mice co-treated with phthalic anhydride (PA) and CKJ for 4 weeks using the IVIS imaging system. A strong luciferase signal was detected in the abdominal region of IL-4/Luc/CNS-1 Tg mice treated with PA alone. However, this signal was significantly reduced in IL-4/Luc/CNS-1 Tg mice co-treated with PA and CKJ. The thymus showed the greatest decrease in luciferase following CKJ treatment, but the level increased after PA treatment. Furthermore, the CKJ-treated group showed improvement of common allergic responses including decreased ear thickness, dermis thickness, auricular lymph node (ALN) weight and infiltrating mast cells. However, IgE concentration and epidermis thickness were maintained a constant level. These results indicated that the luciferase signal may successfully reflect the therapeutic effects of CKJ in IL-4/Luc/CNS-1 Tg mice. The results also suggested that CKJ may be considered an effective substance for the treatment of AD.
\end{abstract}

Correspondence to: Professor Dae Youn Hwang, Department of Biomaterials Science, College of Natural Resources and Life Science/Life and Industry Convergence Research Institute, Pusan National University, 50 Cheonghak-ri, Samnangjin-eup, Miryang-si, Gyeongsangnam-do 627-706, Republic of Korea

E-mail: dyhwang@pusan.ac.kr

Key words: atopic dermatitis, Cheonggukjang, IL-4/Luc/CNS-1 transgenic mice, luciferase, phthalic anhydride

\section{Introduction}

Atopic dermatitis (AD) is a common pruritic inflammatory skin disorder caused by the excessive activation of certain white blood cells and basophils due to IgE production in response to environmental triggers $(1,2)$. AD is diagnosed based on eczematous skin lesions, which present as skin erythematous, plaques, eruption and lichenification, as well as give rise to asthma, allergic rhinitis, administration of food allergies, and contact dermatitis (3-5). Following pathological examination of AD patients, acute lesions show hyperkeratiosis, spongiosis and parakeratosis, while chronic lesions present as epidermal hyperplasia, acanthosis and accumulation of lymphocytes and mast cells in skin tissue $(5,6)$.

Traditional methods have been used to screen allergens among substances in the surrounding environment, although novel methods for screening of allergens have recently received attention owing to their increased presence of environmental allergens. The allergy skin prick test, a well-known traditional method, is an inexpensive, rapid and accurate method measuring allergen response through the use of a few drops of isolated allergen gently pricked onto the surface of the forearm skin to identify causative allergens (7). The allergy-specific IgE antibody test screens allergens by measuring the amounts of IgE antibody for suspected allergens in blood samples $(8,9)$. However, these methods are limited as they do not accurately quantify the magnitude of the allergic response. IL-4/Luc/ CNS-1 transgenic (Tg) mice were recently produced by microinjection with the luciferase gene under control of the human IL-4 promoter and the IL-4 enhancer (CNS-1) to overcome these limitations (10). Three types of allergens were successfully quantified in vivo in these mice, a respiratory sensitizer, vaccine additives, and crude extracts of natural allergens (10). The therapeutic effects of aqueous extract of Liriope platyphylla (AEtLP) on AD were also successfully evaluated using IL-4/Luc/CNS-1 Tg mice (11). Therefore, evaluation of novel substances for their ability to induce AD and the effects of allergens can be conducted using IL-4/Luc/CNS-1 Tg mice. 
Cheonggukjang (CKJ) is a fermented product manufactured from soybean, usually by fermentation with Bacillus subtilis (B. subtilis) (12). During fermentation of CKJ, flavonoid glycosides are converted into aglycones by hydrolysis, and many proteins are degraded into small peptides and amino acids $(13,14)$. CKJ contains many enzymes, microorganisms, and bioactive compounds that are absent from unfermented soybean (15). Additionally, CKJ has various physiological activities caused by antioxidant substances, fibrinolytic enzymes and many active compounds including isoflavones, unsaturated fatty acids, dietary fiber and oligosaccharides (16).

CKJ exhibits diverse biological and pharmacological activities, including anti-mutagenic, anti-obesity and anti-diabetic effects, as well as anti-inflammatory action, fibrinolytic activity and thrombolytic effects on human chronic diseases (17-20). However, few studies have reported the potential efficacy of fermented soybean product or CKJ extract on $\mathrm{AD}$ in humans. Using $\mathrm{NC} / \mathrm{Tnd}$ mice as an $\mathrm{AD}$ model, the ferment soy product, ImmuBalance, was found to reduce AD symptoms including clinical skin severity score, scratching behavior, trans-epidermal water loss (TEWL) value, and PGP9.5-positive neuronal fibers (21). Moreover, the administration of poly- $\gamma$-glutamic acid $(\gamma$-PGA), one of the components of CKJ, significantly decreased the clinical skin severity score, IgE and IgG1 concentration, epidermal thickness, mast cell infiltration and $\mathrm{CCR} 3^{+}$cell number in $\mathrm{NC} /$ Nga mice with BMAC-induced AD (22). Furthermore, the anti-inflammatory activity of the ethanol extract of CKJ was examined in an animal model with passive cutaneous anaphylaxis and arachidonic acid-induced ear edema. Following oral administration of this extract for 5 days, passive cutaneous anaphylaxis was significantly reduced by $27.3 \%$ in a rat group treated with $400 \mathrm{mg} / \mathrm{kg} /$ day (23). However, no studies conducted thus far have used IL-4/Luc/CNS-1 Tg mice with phthalic anhydride (PA)-induced AD as a model to quantify the therapeutic effects of fermented soybean products.

Therefore, the present study was conducted to investigate the use of IL-4/Luc/CNS-1 Tg mice with PA-induced AD to investigate the effects of fermented soybean.

\section{Materials and methods}

Design of animal experiment. The animal protocol used in this study was reviewed and approved based on the ethical and scientific care procedures of the Pusan National University-Institutional Animal Care and Use Committee (PNU-2013-0378). All the animals were handled in the Pusan National University-Laboratory Animal Resources Center accredited by AAALAC International in accordance with the USA NIH guidelines (accredited unit no. 001525) and the Korean Food and Drug Administration (FAD) in accordance with the Laboratory Animals Act (accredited unit no. 00231). The mice were housed under specific pathogen-free (SPF) conditions and a strict light cycle (lights on at 08:00 and off at 20:00) at a temperature of $22 \pm 2^{\circ} \mathrm{C}$ and $50 \pm 10 \%$ relative humidity and were provided with standard irradiated chow diet (Purina Mills Inc., Seongnam, Korea) ad libitum.

Nine-week-old IL-4/Luc/CNS-1 Tg mice $(\mathrm{n}=20)$ were randomly divided into four groups, with five mice per group. The first group of $\mathrm{Tg}$ mice [acetone-olive oil (AOO), $\mathrm{n}=5$ ] had $100 \mathrm{ml}$ of AOO repeatedly spread on the dorsum of their ears three times a week for 4 weeks. In the second group (PA, $\mathrm{n}=10), 100 \mathrm{ml}$ of $15 \%$ PA solution in AOO (4:1, v/v) was repeatedly spread on the dorsum of the ears three times a week for 4 weeks. The second group was further divided into the PA + Vehicle and PA + CKJ treatment groups, which received a comparable volume of water daily via oral administration and $50 \mathrm{mg} / \mathrm{kg}$ body weight of CKJ for 4 weeks, respectively. Age-matched Tg mice $(n=5)$ were used as a no treatment group.

IL-4/Luc/CNS-1 Tg mice. IL-4/Luc/CNS-1 Tg mice used in this study were obtained from the National Institute of Food and Drug Safety Evaluation of the Korean FDA (Osong, Korea). Large numbers of IL-4/Luc/CNS-1 Tg mice and non-Tg littermates were produced by mating IL-4/Luc/CNS- $1 \mathrm{Tg}$ mice and HR 1 mice. Founder mice, into which the $I L-4 / L u c / C N S-1$ transgene was inserted, were identified by PCR analysis of tail-derived genomic DNA. For PCR, $10 \mathrm{pmol}$ each of sense (5'-CTC GCA TGC CAG AGA TCC TA-3') and antisense (5'-CCA CAA CCT TCG CTT CAA AA-3') primers were added into a mixture containing genomic DNA template, and the reaction mixtures were subjected to 35 cycles of amplification $\left(1 \mathrm{~min}\right.$ at $94^{\circ} \mathrm{C} ; 1 \mathrm{~min}$ at $56^{\circ} \mathrm{C}$ and $1 \mathrm{~min}$ at $\left.72^{\circ} \mathrm{C}\right)$ using a Perkin-Elmer thermal cycler (PerkinElmer, Waltham, MA, USA). The amplified PCR products were separated by $1 \%$ agarose gel electrophoresis and band patterns were detected using a Kodak Electrophoresis Documentation and Analysis System 120 (Eastman Kodak, Rochester, NY, USA). IL-4/Luc/CNS-1 Tg mice were screened from founder mice through the detection of PCR products with $467 \mathrm{bp}$.

Preparation of CKJ extracts. CKJ extract was prepared as previously described $(24,25)$. The soybean (Daepung strain) used to manufacture CKJ was kindly supplied by the National Institute of Crop Science (Miryang, Korea) while B. subtilis MC31 was obtained from the Food Microbiology Laboratory at Pusan National University. To manufacture the CKJ extract, $15 \mathrm{~g}$ of soybeans were washed and then soaked in three volumes of tap water at room temperature for $24 \mathrm{~h}$. The soybeans were then treated with hot steam at $121^{\circ} \mathrm{C}$ for $50 \mathrm{~min}$, after which they were allowed to cool to $45^{\circ} \mathrm{C}$. The steamed soybeans were inoculated with $2 \%(\mathrm{w} / \mathrm{w})$ B. subtilis MC31 and fermented for $72 \mathrm{~h}$ at $40^{\circ} \mathrm{C}$. The fermented soybeans were then powdered by freeze-drying, homogenization and sifting. The final sample of CKJ extract was stored at $-75^{\circ} \mathrm{C}$ until use.

Analysis of GABA concentration. GABA concentration was measured in a spectrophotometric assay containing GABase enzyme (Sigma-Aldrich, St. Louis, MO, USA) using the method described by Zhang and Bown (26). Briefly, the supernatant of the CKJ extract was collected from the lyophilized powder of CKJ $(0.3 \mathrm{~g})$ that had been soaked in $99 \%$ ethanol $(1.2 \mathrm{ml})$ for $5 \mathrm{~h}$. This supernatant $(0.1 \mathrm{ml})$ was then mixed with $0.4 \mathrm{ml}$ of $\mathrm{MeOH}$ and completely dried at $70-80^{\circ} \mathrm{C}$ for $30 \mathrm{~min}$. Then, $70 \mathrm{mM} \mathrm{LaCl}_{3}(1 \mathrm{ml})$ was added and the mixture was agitated for $10 \mathrm{~min}$, centrifuged at $9,800 \mathrm{x} \mathrm{g}$ for $5 \mathrm{~min}$. The supernatant $(0.8 \mathrm{ml})$ was then mixed with $0.1 \mathrm{M} \mathrm{KOH}$ solution $(0.16 \mathrm{ml})$ for 3-5 min, after which it was purified by centrifugation and filtration. This solution $(0.55 \mathrm{ml})$ of CKJ was then 
dispensed into individual cuvettes, each of which contained $0.2 \mathrm{ml}$ of $0.5 \mathrm{mM} \mathrm{K}_{4} \mathrm{P}_{2} \mathrm{O}_{7}$ buffer ( $\mathrm{pH} \mathrm{8.6),} 0.15 \mathrm{ml}$ of $4 \mathrm{mM}$ NADP and $0.05 \mathrm{ml}$ of GABase $(2 \mathrm{U} / \mathrm{ml})$. The initial absorbance was then read at $340 \mathrm{~nm}$ using a spectrophotometer (Optizen POP; Mecasys Co., Ltd., Daejeon, Korea), after which $0.05 \mathrm{ml}$ of $20 \mathrm{mM} \alpha$-ketoglutarate was added and the samples were incubated for $60 \mathrm{~min}$ at room temperature. The absorbance was read at the same wavelength. The final concentration of GABA was then calculated by comparing the differences of the two absorbances and by comparison with a standard curve.

High-performance liquid chromatography (HPLC) analysis of $C K J$. To determine the concentration of diadzein and genistein in $\mathrm{CKJ}$, the aqueous extract of $\mathrm{CKJ}$ was dissolved in $100 \mathrm{mg} / \mathrm{ml}$ of $50 \% \mathrm{MeOH}$ and agitated at $200 \mathrm{rpm}$ for $4 \mathrm{~h}$. Following incubation for $12 \mathrm{~h}$ at room temperature, the sample was centrifuged at 3,000 rpm, after which the supernatant was harvested, diluted to $25 \mathrm{mg} / \mathrm{ml}$ in $50 \% \mathrm{MeOH}$ and passed through a syringe filter $(0.45 \mathrm{~mm})$.

The CKJ was analyzed using an iLC 3000 HPLC system (Interface Engineering Co., Ltd., Seoul, Korea) equipped with a Corona ${ }^{\circledR}$ CAD $^{\circledR}$ Detector (ESA Bioscience, Inc., Chelmsford, MA, USA). Chromatographic separation was performed using a YMC-triart C18 column $(4.6 \times 250 \mathrm{~mm}$, particle size $5 \mu \mathrm{m}$; Shiseido Co., Ltd., Tokyo, Japan). The mobile phase consisted of solvent A $(0.1 \%$ formic acid in deionized water) and solvent B (acetonitrile) using the following gradient elution program: $0-30 \mathrm{~min}, 20-40 \%$ of solvent B and $30-45 \mathrm{~min}, 40-70 \%$ of solvent $\mathrm{B}$. A flow rate of $1.0 \mathrm{ml} / \mathrm{min}$ was used for sample analysis and the nebulizer gas was nitrogen. The gas flow rate and gas pressure were maintained at $1.531 / \mathrm{min}$ and $35 \pm 2$ psi, respectively. The output signal of the detector was recorded using the Clarity ${ }^{\mathrm{TM}}$ Chromatography Software (DataApex, Prague, Czech Republic).

Measurement of body weight, organ weight and ear thickness. Alterations of body weight during the experimental procedure were measured using an electronic balance (Mettler Toledo-International, Inc., Greifensee, Switzerland) three times a week for 4 weeks. After final administration, the weights of the spleen, thymus, auricular lymph node (ALN) collected from the sacrificed mice were also measured by the same method. Ear thickness was measured using a thickness gauge (Digimatic Indicator; Matusutoyo Co., Tokyo, Japan) to determine the degree of allergic skin inflammation induced by PA treatment.

Analysis of the bioluminescence image. In vivo imaging was conducted using an IVIS imaging system (Xenogen Corp., Alameda, CA, USA) as previously described (11). Briefly, IL-4/Luc/CNS-1 Tg mice were anesthetized with Zoletil and injected i.p. with $150 \mathrm{mg} / \mathrm{kg}$ of D-luciferin (Sigma-Aldrich). Ten minutes after the D-luciferin injection, images of mice were captured for 3 min using an IVIS imaging system. Photons emitted from specific regions were then quantified using the Living Image software (Xenogen Corp.). In vivo luciferase activity was expressed in photons per second.

Enzyme-linked immunosorbent assay (ELISA) for the detection of serum IgE concentration. The serum IgE concentration was measured using an ELISA kit (Shibayagi, Co., Ltd., Gunma, Japan) according to the manufacturer's instructions. Briefly, capture antibodies were plated in the Nunc C bottom immunoplate supplied in the kit. The wells were then washed with washing solution $(50 \mathrm{mM}$ Tris, $0.14 \mathrm{M} \mathrm{NaCl}, 0.05 \%$ Tween-20, $\mathrm{pH}$ 8.0) three times, after which serum samples and standards diluted with buffer solution were added to the wells, and the plate was incubated for $2 \mathrm{~h}$. The wells were then washed again with washing solution, after which $50 \mu \mathrm{l}$ of biotin-conjugated anti-IgE antibodies (1,000-fold dilution) were added to each well and the samples were incubated for another $2 \mathrm{~h}$ to bind with captured IgE. The wells were then washed again with washing solution, after which horseradish peroxidase-conjugated detection antibodies $(2,000$-fold dilution) were added to each well and samples were incubated for $1 \mathrm{~h}$. An enzyme reaction was then initiated by adding tetramethylbenzidine (TMB) substrate solution (100 mM sodium acetate buffer $\mathrm{pH} 6.0,0.006 \% \mathrm{H}_{2} \mathrm{O}_{2}$ ) and the samples was incubated at room temperature in the dark for $20 \mathrm{~min}$. The reaction was terminated by adding acidic solution (reaction stopper, $1 \mathrm{M} \mathrm{H}_{2} \mathrm{SO}_{4}$ ), and the absorbance of yellow product was measured spectrophotometrically at $450 \mathrm{~nm}$. The final concentration of IgE was calculated using a standard curve.

Histological analysis of ear tissue. Ear tissues were removed from mice, fixed with $10 \%$ formalin, embedded in paraffin wax, routinely processed, and sectioned into $4 \mu \mathrm{m}$ slices. The ear tissue sections were then stained with hematoxylin and eosin, after which they were examined by light microscopy (Leica Microsystems, Heerbrugg, Switzerland) for the presence of edema and inflammatory cell accumulation. Thickness levels of the epidermis and dermis and the number of crypts were also measured using the Leica Application Suite (Leica Microsystems).

Mast cells were detected by staining with Toluidine blue (Sigma-Aldrich) according to previously described methods (27). Subsequent to deparaffinization and dehydration, ear tissue sections were stained with $0.25 \%$ Toluidine blue (Sigma-Aldrich) and examined by light microscopy for the presence of mast cells. The number of cells per specific area was measured with Leica Application Suite (Leica Microsystems).

Western blot analysis. Ear tissues from a subset of the groups ( $\mathrm{n}=5$ per group) were homogenized using a PRO-PREP ${ }^{\mathrm{TM}}$ Solution kit (Intron Biotechnology, Seongnam, Korea) supplemented with $1 / 2$ of a protein inhibitor cocktail tablet (Roche Diagnostics GmbH, Penzberg, Germany), followed by centrifugation at 13,000 rpm for $5 \mathrm{~min}$. The prepared proteins were then electrophoresed through a $10 \%$ SDS-PAGE gel. The proteins were transferred onto a nitrocellulose membrane (Amersham Biosciences, Corston, UK) for $2 \mathrm{~h}$ at $40 \mathrm{~V}$ in transfer buffer (25 mM Trizma-base, $192 \mathrm{mM}$ glycine and $20 \%$ methanol). The efficiency of the transfer and equal protein loading were determined by staining the gel with Coomassie Blue (Sigma-Aldrich). Appropriate dilutions of primary antibodies, anti-IL-6 antibody (Santa Cruz Biotechnology, Inc., Santa Cruz, CA, USA), anti-VEGF antibody (Peprotech, Inc., Rocky Hill, NJ, USA), and anti- $\beta$-actin (Sigma-Aldrich) were added to the membranes and allowed to hybridize overnight at $4^{\circ} \mathrm{C}$. After the antibodies were removed, the membranes 
were washed three times in a solution composed of $10 \mathrm{mM}$ Trizma-base ( $\mathrm{pH} 7.6), 150 \mathrm{mM} \mathrm{NaCl}$, and $0.05 \%$ Tween-20 for $10 \mathrm{~min}$. This was followed by incubation with horseradish peroxidase-conjugated anti-secondary antibody for $1 \mathrm{~h}$ at room temperature. The membrane was washed again as described above and developed using an enhanced chemiluminescence detection system (Amersham Bioscience). The results were then quantified using the Image Analyzer System (2000MM; Estman Kodak) and expressed as the fold-increase over control values. Results were confirmed by two independent investigators who performed the experiments at least twice.

Statistical analysis. One-way ANOVA was used to identify significant differences between the PA- and AOO-treated groups (SPSS for Windows, Release 10.10, Standard Version; SPSS, Inc., Chicago, IL, USA). Additionally, response differences between the Vehicle- and CKJ-treated group in the PA-treated group were evaluated by a post hoc test (SPSS for Windows, Release 10.10, Standard Version; SPSS, Inc.) of the variance and significance levels. All the values are expressed as the means \pm standard deviation $(\mathrm{SD}) . \mathrm{P}<0.05$ was considered to indicate statistical significance.

\section{Results}

Distribution of key components in CKJ. The distribution of three functional compounds in CKJ was analyzed by enzyme assay and HPLC analysis. GABA was found to be present at $200.00 \mu \mathrm{g} / \mathrm{g}$, while the levels of the flavonoids daidzein and genistein were 85.68 and $132.51 \mu \mathrm{g} / \mathrm{g}$, respectively (Fig. 1). Therefore, above results indicated that CKJ extract contained high concentrations of GABA although the concentration of flavonoids was slightly low.

Effects of CKJ-treatment on ear morphology and thickness. To determine whether CKJ treatment suppressed changes in ear phenotype induced by PA treatment, ear morphology and thickness were observed in IL-4/Luc/CNS-1 Tg mice after CKJ treatment for 4 weeks. The outline of the ear vein became distinct or thickened in the PA + Vehicle-treated group compared to the AOO-treated group, and ear color changed from flesh tint to dark brown. These alterations were slightly reversed in the PA + CKJ co-treated group (Fig. 2B). In addition, ear thickness rapidly increased in PA + Vehicle-treated mice compared to non- or AOO-treated mice. However, these levels in PA + CKJ-treated mice were significantly lower than those in the PA + Vehicle-treated group (Fig. 2C). Therefore, these findings demonstrated that CKJ treatment successfully decreases ear and vein thickness induced by PA-treatment.

Quantification of the therapeutic effects of CKJ treatment in IL-4/Luc/CNS-1 Tg mice treated with PA. To quantify the therapeutic effects of CKJ on the allergenic response to PA treatment using the luciferase reporter system, luciferase signals from the whole body and eight organs were measured using the Living Image software in IL-4/Luc/CNS-1 Tg mice after individual PA + Vehicle or PA + CKJ treatment. In the whole body image, the luciferase signal was highly detected in the abdominal region of IL-4/Luc/CNS-1 Tg mice treated with PA + Vehicle, whereas the no treatment or AOO-treated
A

\begin{tabular}{lc}
\hline & Concentration $(\mu \mathrm{g} / \mathrm{g})$ \\
\hline GABA & 200.00 \\
Daidzein & 85.68 \\
Genistein & 132.51 \\
\hline
\end{tabular}

B

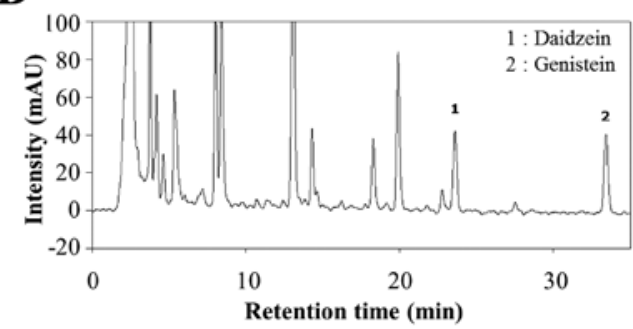

Figure 1. Distribution of major components in cheonggukjang (CKJ). (A) The concentration of GABA, daidzein and genistein was measured as described in the 'Materials and methods'. (B) Daidzein and genistein in CKJ were detected at corresponding retention times in high-performance liquid chromatography (HPLC).
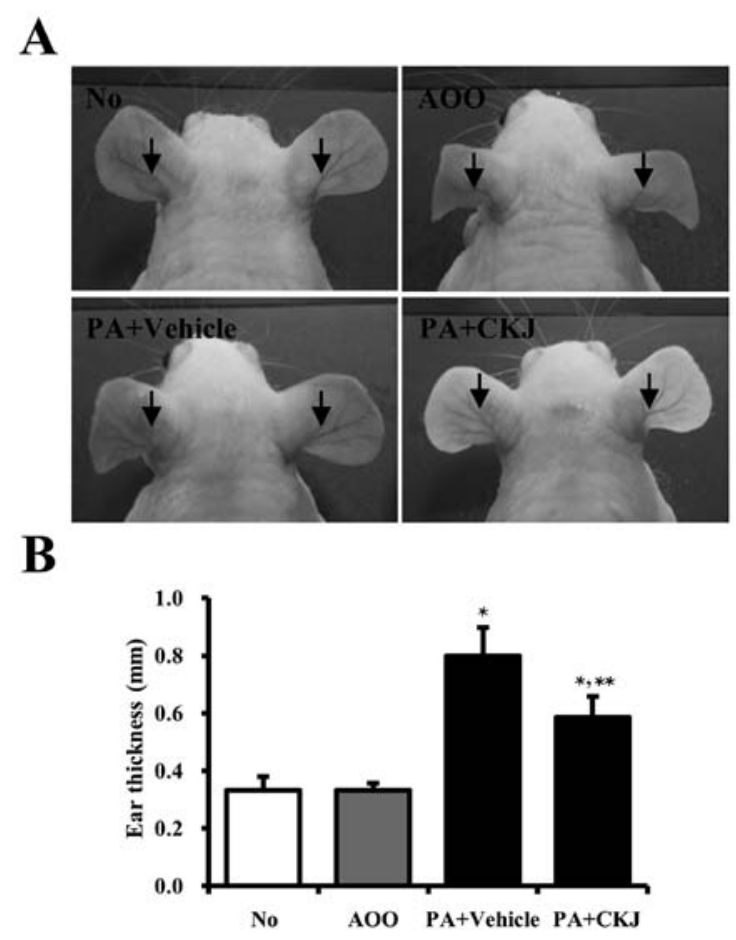

Figure 2. Differences in ear phenotypes and ear thickness. (A) Ear phenotypes of mice in the four groups were observed by photo images taken during the repeated application of phthalic anhydride (PA) + cheonggukjang (CKJ). Arrows indicate the ear vein. PA solution was repeatedly applied to the dorsum of ears of IL-4/Luc/CNS-1 transgenic (Tg) mice during oral gavage of CKJ. (B) After 4 weeks, ear thickness was observed as described in 'Materials and methods'. Data shown are the means \pm standard deviation (SD) $(n=5)$. ${ }^{*} \mathrm{P}<0.05$ indicates a significant difference compared to the acetone-olive oil (AOO)-treated group. ${ }^{* *} \mathrm{P}<0.05$ indicates a significant difference compared to the PA + Vehicle-treated group.

group showed no luciferase signal. However, this signal was greatly reduced in groups treated with PA + CKJ (Fig. 3A). Following organ image analysis, a high luciferase signal 
A

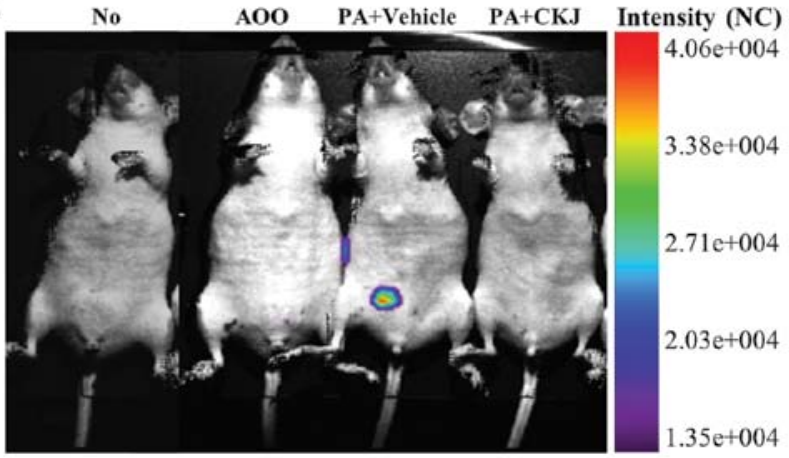

B

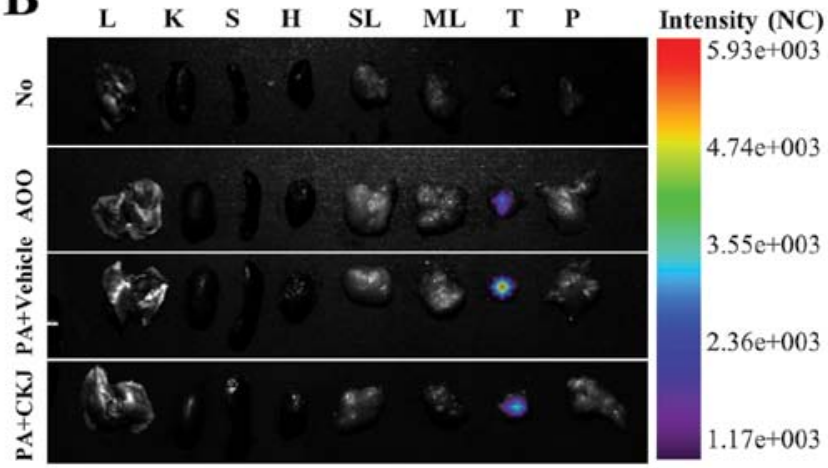

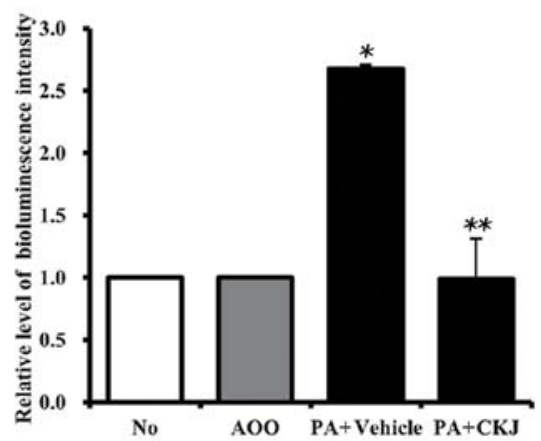

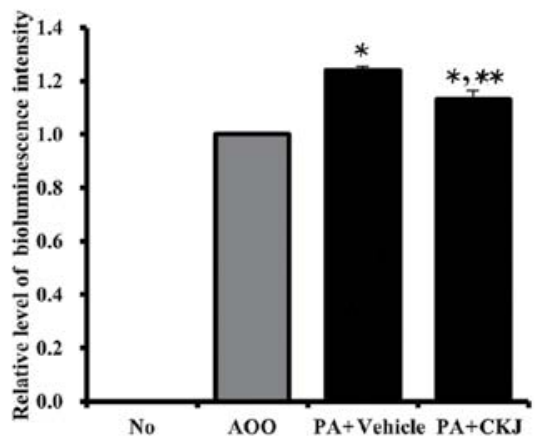

Figure 3. (A) Detection of luciferase signals in the whole body and (B) each organ of IL-4/Luc/CNS-1 transgenic (Tg) mice. Mice were treated with acetone-olive oil (AOO), phthalic anhydride (PA) + Vehicle and PA + cheonggukjang (CKJ) for 4 weeks and then imaged at $24 \mathrm{~h}$ after final treatment using the Living Image software. Color overlay on the image represents the photons per second emitted from the organs in accordance with the pseudocolor scale shown next to the image. In this image, red indicates the highest number of photons per second, while blue indicates the lowest number of photons per second. L, lung; K, kidney; S, spleen; H, heart; SL, submandibular lymph node; ML, mesenteric lymph node; T, thymus; P, pancreas. Data shown are the means \pm standard deviation (SD) $(\mathrm{n}=5) .{ }^{*} \mathrm{P}<0.05$ indicates a significant difference compared to the AOO-treated group. ${ }^{* *} \mathrm{P}<0.05$ indicates a significant difference compared to the PA + Vehicle-treated group.

was detected in the thymus of IL-4/Luc/CNS-1 Tg mice treated with PA + Vehicle, however, the signal was markedly reduced in the thymus of IL-4/Luc/CNS-1 Tg mice treated with PA + CKJ (Fig. 3B). Overall, these results indicated that the effects of CKJ on the allergic response induced by PA treatment could be quantified using IL-4/Luc/CNS-1 Tg mice without sacrificing the animals.

Alteration of body and organ weight. Alterations in body weight were measured during all experimental periods to examine the effects of CKJ treatment on whole body growth. However, no significant changes in body weight were in observed in any of the groups (Fig. 4A).

It is well known that the weight of some immune organs increase in response to the topical application of agents that have allergenic or sensitizing potential $(28,29)$. As shown in Fig. 4B and C, PA treatment induced an increase in the weight of the spleen and lymph node in IL-4/Luc/CNS-1 Tg mice compared to the AOO-treated group. However, their weights were significantly reduced in the PA + CKJ-treated group, although not to the level of the AOO-treated group. The weight of the thymus was maintained in the PA + Vehicle and PA + CKJ-treated group (Fig. 4D). Taken together, these results suggested that $\mathrm{CKJ}$ treatment contributes to the reduction of spleen and lymph node weight observed in IL-4/Luc/ CNS-1 Tg mice in response to PA treatment.
Effects of CKJ treatment on ear histology. To verify the suppressive effects of CKJ treatment on ear histology, the histological analysis of ear tissue from IL-4/Luc/CNS-1 $\mathrm{Tg}$ mice was performed. The epidermis and dermis of the ear tissue were thicker in the PA + Vehicle-treated group than in the AOO-treated group. The thickness of the dermis greatly decreased in the PA + CKJ-treated group, but was not completely recovered to that of the AOO-treated group (Fig. 5A and $\mathrm{Bb}$ ). The thickness of the epidermis increased in the PA + CKJ-treated group compared to the $\mathrm{PA}+$ Vehicle-treated group (Fig. 5A and $\mathrm{Ba}$ ). Taken together, these results showed that CKJ may improve the dermis thickness among the AD responses induced by PA-treatment.

Effects of CKJ treatment on infiltration of mast cells. Mast cells play important roles in asthma, eczema, itch, allergic rhinitis, and allergic conjunctivitis (30). Therefore, ear tissue sections were stained with Toluidine blue and observed under a microscope to examine the effects of CKJ on the infiltration of mast cells. The number of mast cells stained blue was significantly greater in the PA + Vehicle-treated group than that in the AOO-treated group (Fig. 6). However, their number was significantly reduced following PA $+\mathrm{CKJ}$-treatment, although not to that of the AOO-treated group (Fig. 6A and $\mathrm{Ba}$ ). These data suggest that CKJ contributes to the suppression of mast cell infiltration in the dermis of ear skin. 
A

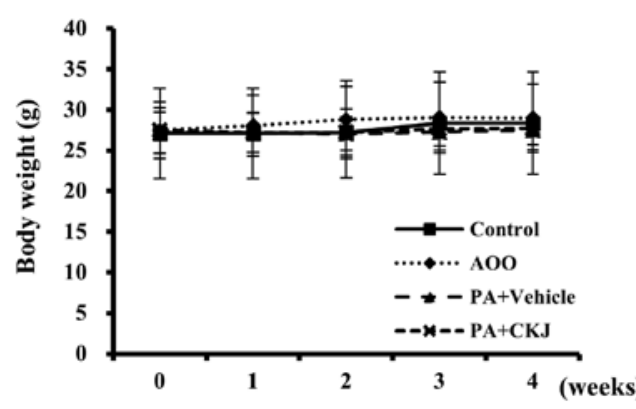

B

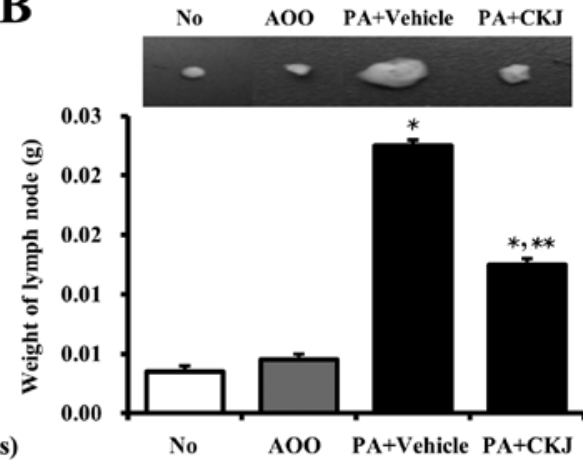

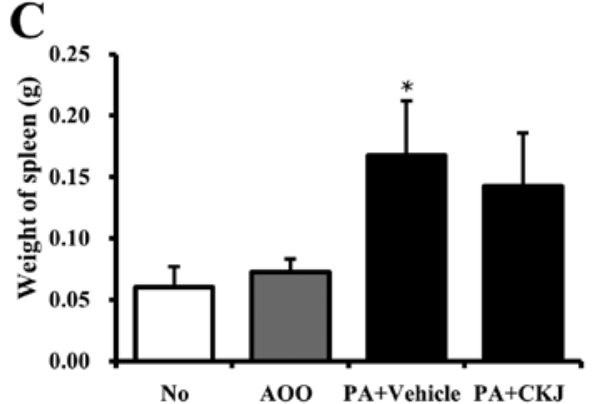

D

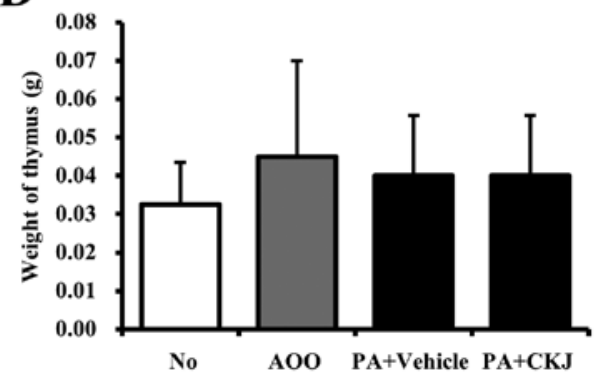

Figure 4. Differences in body and organ weight. (A) Body weight of mice in the four groups were measured with a chemical balance. Phthalic anhydride (PA) solution was repeatedly applied to the dorsum of ears of IL-4/Luc/CNS-1 transgenic (Tg) mice during oral gavage of cheonggukjang (CKJ). After final administration, mice from each group were sacrificed under anesthesia. (B) The auricular lymph nodes (ALN) were then harvested from the neck regions of the mice using a microscissor, after which they were weighed using a chemical balance. (C) The spleen and (D) thymus weight were analyzed using a chemical balance. Data shown are the means \pm standard deviation $(\mathrm{SD})(\mathrm{n}=5)$. $\mathrm{P}<0.05$ indicates a significant difference compared to the acetone-olive oil (AOO)-treated group. ${ }^{* *} \mathrm{P}<0.05$ indicates a significant difference compared to the $\mathrm{PA}+$ Vehicle-treated group.

The serum IgE concentration was measured in the four groups of mice to determine whether CKJ suppressed the allergic response induced by PA treatment. Repeated topical application of PA solution induced a significant increase in serum IgE concentration in IL-4/Luc/CNS-1 Tg mice. However, a significant decrease of IgE concentration was not observed in the PA + CKJ-treated group (Fig. 6Bb). Overall, these results suggested that $\mathrm{CKJ}$ treatment did not contribute to the reduction of IgE concentration in IL-4/Luc/CNS-1 Tg mice observed in response to PA treatment.

Effects of CKJ treatment on cytokine expression. To determine whether CKJ induced the alteration of atopic response-related cytokine expression, the expression levels of VEGF and IL-6 were measured in ear tissues of IL-4/Luc/CNS-1 Tg mice. A high expression of VEGF protein was observed in the $\mathrm{PA}+$ Vehicle-treated group, whereas a low expression was detected in the AOO-treated group and a reduction of VEGF protein expression was observed in the PA + CKJ-treated group (Fig. 7A and Ba). Similar results were observed following analysis of IL-6 expression. The increased IL-6 expression after PA treatment was reversed by CKJ treatment, but not to levels of the AOO-treated group (Fig. 7A and Bb). The above results suggested that $\mathrm{CKJ}$ treatment may relieve the allergic response induced by PA treatment through the regulation of VEGF and IL-6 expression.

\section{Discussion}

Many Tg animal models characterizing allergic skin inflammation have been developed and established to assess immunity in vivo. These models can be classified into three groups: i) models induced by epicutaneous (EC) application of sensitizers, ii) Tg mice that either overexpress or defect selective proteins, and iii) mice that spontaneously develop AD-like skin lesions (5). In the first group, an animal model of AD is induced by skin injury and EC sensitization with allergens including ovalbumin (OVA) and PA. Following sensitization, these models exhibit increased scratching behavior, enhanced epidermal and dermal thickness, infiltration of $\mathrm{CD}^{+} \mathrm{T}$ cells, and a high expression of Th2 cytokines (31). Similar phenotypes can be induced by EC application of house dust mite allergens, haptens such as oxazolone and trinitrochlorobenzene treatment, and superantigen treatment (32-34). In the second group, most animal models of $\mathrm{AD}$ are produced by the overexpression of several related genes [IL-4, IL-31, thymic stromal lymphopoietin (TSLP), caspase-1 and IL-18], as well as specific genes such as RelB and cathepsin. These models also develop chronic dermatitis accompanied with acanthosis, spongiosis, hyperkeratosis, dermal infiltration and accumulation of mast cells, although their phenotypes do not remain common in each mouse (35-40). Additionally, strains of mice such as Naruto Research Institute Otsuka Atrichia (NOA), NC/Nga and DS-Ng have been proposed as AD models as they spontaneously develop AD-like phenotypes during the breeding period $(41,42)$. Our study focused on quantification of therapeutic effects of a treatment for $\mathrm{AD}$ using the luciferase system in IL-4/Luc/CNS-1 Tg mice. Since most previous studies have been biased by the therapeutic substance screened and investigation of their mechanism using the above model for $\mathrm{AD}$, the present study is important to understand the therapeutic effects of CKJ extract that help improve AD 
A

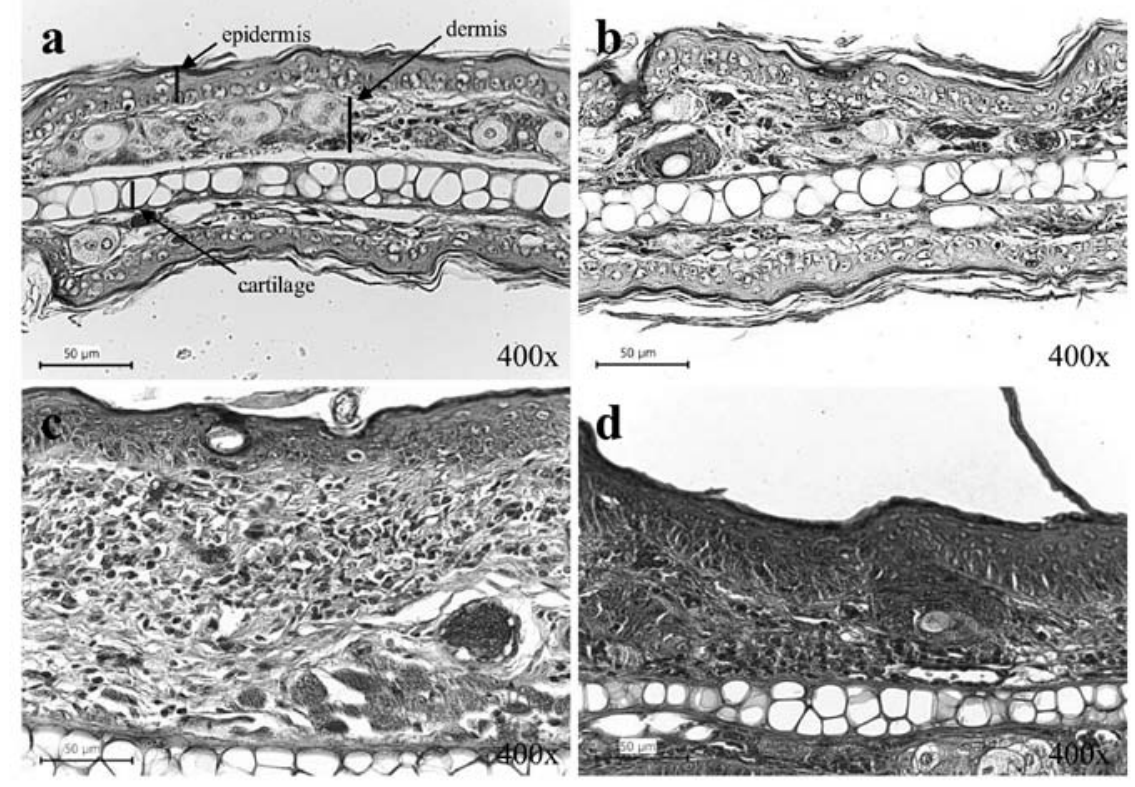

B
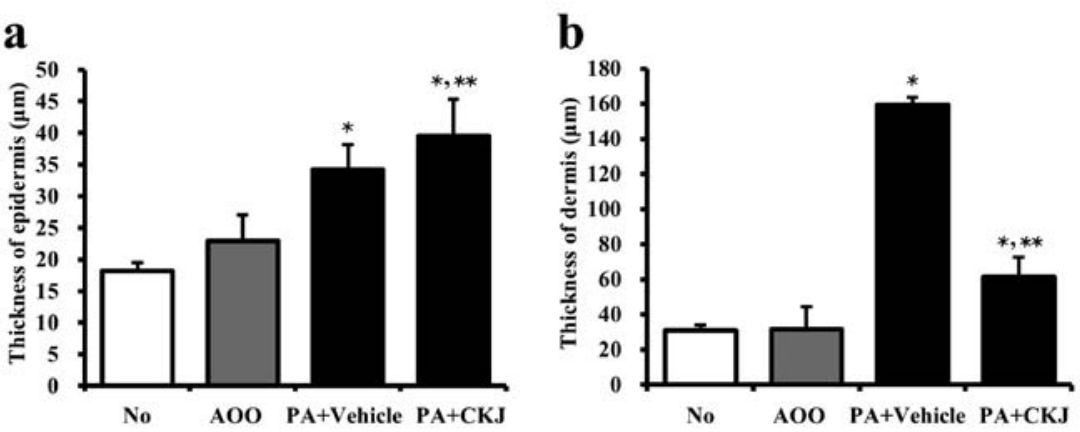

Figure 5. Histopathology of ear tissue in IL-4/Luc/CNS-1 transgenic (Tg) mice (A-a) with no treatment (No), and those treated with (A-b) acetone-olive oil (AOO), (A-c) phthalic anhydride (PA) + Vehicle, and (A-d) PA + cheonggukjang (CKJ). PA solution was repeatedly applied to the dorsum of ears of IL-4/ Luc/CNS-1 Tg mice during oral gavage of CKJ. After 4 weeks, histological changes were observed as described in 'Materials and methods'. (A) Slide sections of ear tissue were stained with hematoxylin and eosin and observed at x400 magnification. (B-a) The average thickness of the epidermis and (B-b) dermis are presented as graphs. Data shown are the means \pm standard deviation (SD) $(n=5)$. ${ }^{*} \mathrm{P}<0.05$ indicates a significant difference compared to the AOO-treated group. ${ }^{* * *} \mathrm{P}<0.05$ indicates a significant difference compared to the $\mathrm{PA}+$ Vehicle-treated group.

in humans. However, it should be noted that the present study was limited in that it only provided information regarding the effects of CKJ during 4 weeks. Accordingly, further long-term investigations and human clinical trials are needed to clearly verify the therapeutic effects of CKJ and apply the findings presented in this study to humans.

In most animal models, adverse effects on skin have been detected and improved by treatment with several therapeutic substances $(11,27,43)$. Some fermented soybean products have been shown to alleviate adverse skin conditions in the AD model. For example, treatment with ImmuBalance for two weeks gradually reduced the clinical skin severity scores in NC/Tnd mice (21). Additionally, a significant decrease in the clinical skin severity score was detected in mice treated with low-molecular $\gamma$-PGA (PGA-LM) for three weeks (22). The results of the present study are in agreement with the abovementioned previous reports, although the rate of decrease varied. This difference may have occurred because the current study used the aqueous extract of CKJ as the therapeutic substance, whereas the above studies utilized a specific compound purified from fermented soybean products.
Histological alterations of the epidermis and dermis thickness, mast cell infiltration and immune cell accumulation are considered key effects in IgE-mediated immediate hypersensitivity and allergic disorders, as well as in immune responses that protect organisms from parasites and bacteria $(44,45) . \mathrm{NC} /$ Nga mice treated with PGA-LM were found to have lower epidermis thickness, mast cell infiltration and $\mathrm{CCR}^{+}$cell concentrations than a control group (22). Similarly, the number of PGP9.5-positive neuronal fibers was decreased in the lesion skin of NC/Tnd mice after ImmuBalance treatment (21), while passive cutaneous anaphylaxis was reduced by the ethanol extract of CKJ (23). To the best of our knowledge, the results of the present study are the first to demonstrate the therapeutic effects of CKJ aqueous extract on alteration of AD phenotypes in IL-4/Luc/CNS-1 Tg mice. The thickness of dermis and infiltrating mast cells decreased in the PA + CKJ-treated group when compared with the PA + Vehicle-treated group, although the epidermis thickness was maintained at a constant level, which is partially in agreement with results of a previous study.

Hyperproduction of $\operatorname{IgE}$ is one of the key markers of allergic hypersensitivity (46), as well as an indicator of the 
A

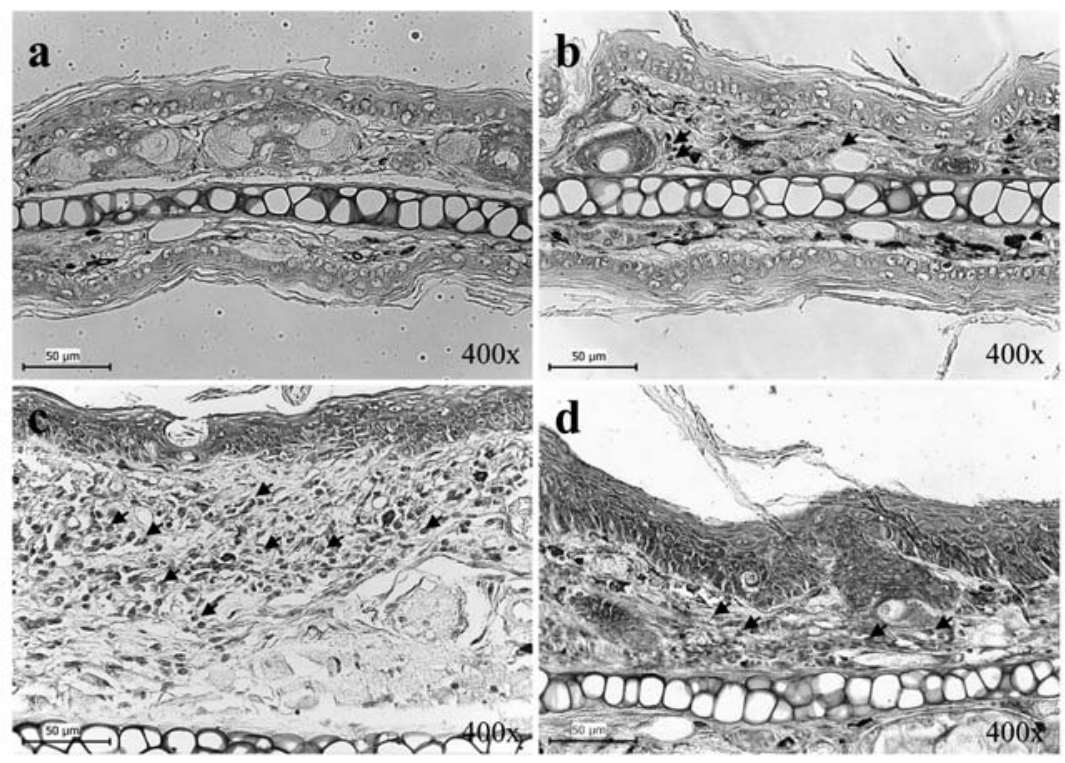

B

a

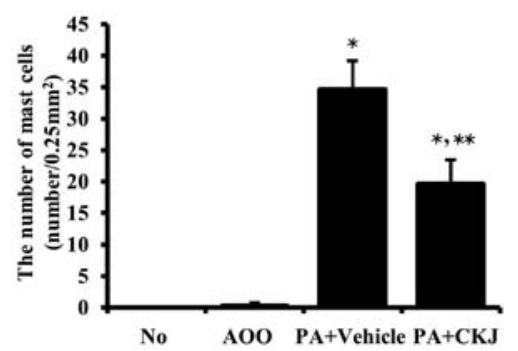

b

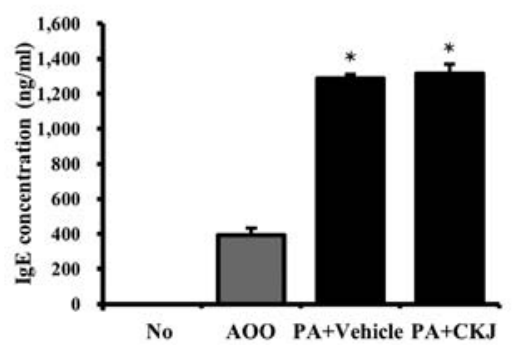

Figure 6. Infiltration of mast cells in IL-4/Luc/CNS-1 transgenic (Tg) mice (A-a) with no treatment (No), and those treated with (A-b) acetone-olive oil (AOO), (A-c) phthalic anhydride (PA) + Vehicle, and (A-d) PA + cheonggukjang (CKJ). (A) Slide sections of ear tissue were stained with $0.25 \%$ Toluidine blue and observed at x400 magnification. Arrows indicate infiltrated mast cells in the dermis of ear. (B-a) The average number of mast cells is presented as a graph. (B-b) Serum used to measure the IgE concentration was prepared from blood samples collected from the abdominal veins of mice. Serum IgE concentration was quantified by enzyme-linked immunosorbent assay (ELISA). Data shown are the means \pm standard deviation (SD) $(\mathrm{n}=5)$. ${ }^{*} \mathrm{P}<0.05$ indicates a significant difference compared to the AOO-treated group. ${ }^{* *} \mathrm{P}<0.05$ indicates a significant difference compared to the PA + Vehicle-treated group.

A

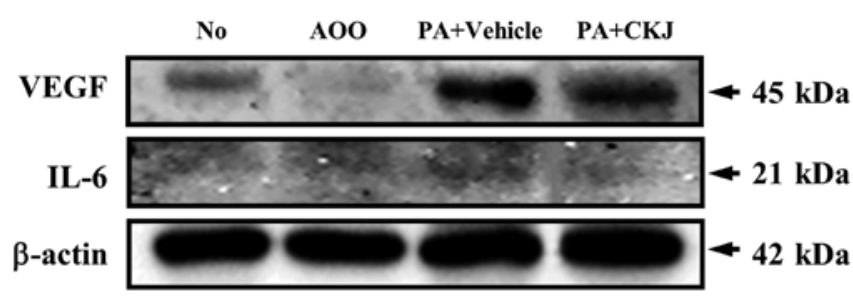

B
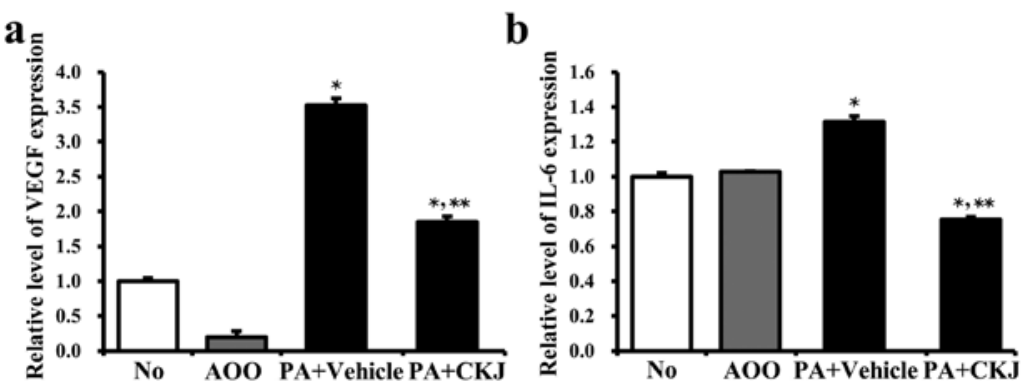

Figure 7. Expression of VEGF and IL-6 in lymph nodes. (A) Alteration of the expression of the two proteins was measured by western blot analysis. After the intensity of each band was determined using an imaging densitometer, (B) the relative level of each protein was calculated based on the intensity of actin protein. Data shown are the means \pm standard deviation (SD) from three replicates. " $\mathrm{P}<0.05$ indicates a significant difference compared to the acetone-olive oil (AOO)-treated group. ${ }^{* *} \mathrm{P}<0.05$ indicates a significant difference compared to the phthalic anhydride (PA) + Vehicle-treated group. 
magnitude of allergic immune response, including AD (47). Administration of PGA-LM induced a significant decrease in $\mathrm{IgE}$ and IgG1 concentration compared to a control group in previous studies $(21,22)$. In the present study, IgE concentration was not affected by CKJ treatment. This difference was likely due to the main components of CKJ, the sample preparation method and bacteria strain used for fermentation in the various studies.

To the best of our knowledge, this is the first study to employ IL-4/Luc/CNS-1 Tg mice to quantify the therapeutic effects of AEtLP on the allergenic response to PA treatment. The luciferase signal was highly detected in the abdominal region of IL-4/Luc/CNS-1 Tg mice treated with PA + Vehicle alone, whereas the AOO-treated group showed no luciferase signal. However, this signal was greatly reduced in groups treated with PA + AEtLP25 and PA + AEtLP50. Moreover, the highest luciferase signals were detected in the thymus, followed by the pancreas and SL of IL-4/Luc/CNS-1 Tg mice treated with PA + Vehicle, whereas these signals were markedly reduced in these organs in IL-4/Luc/CNS-1 Tg mice treated with PA + AEtLP25 or PA + AEtLP50 (11). In the present study, CKJ treatment induced a marked decrease of luciferase signal in the abdominal region of IL-4/Luc/CNS-1 Tg mice, as shown in Fig. 3. Moreover, this signal decreased in the thymus of IL-4/Luc/CNS-1 Tg mice treated with $\mathrm{PA}+\mathrm{CKJ}$. These results were consistent with previous results published by our group (11), although the pancreas and SL showed different levels.

Taken together, the results of this study have demonstrated two novel findings regarding the therapeutic effects of CKJ using IL-4/Luc/CNS-1 Tg mice. Specifically, IL-4/Luc/CNS-1 $\mathrm{Tg}$ mice may be successfully applied to screen for the therapeutic effects of CKJ-related products. Additionally, the aqueous extract of CKJ can effectively relieve AD induced by PA treatment. Furthermore, the findings presented herein indicate that CKJ may be a beneficial food for the improvement and prevention of AD.

\section{Acknowledgements}

We thank Jin Hyang Hwang for directing the animal management and care at the Laboratory Animal Resources Center. This study was supported by grants to Dae Youn Hwang from the Korea Institute of Planning Evaluation for Technology of Food, Agriculture, Forestry and Fisheries (111030-3).

\section{References}

1. Hanifin JM and Rajka G: Diagnostic features of atopic dermatitis Acta Derm Venereol Suppl (Stockh) 92: 44-47, 1980.

2. Leung DY and Bieber T: Atopic dermatitis. Lancet 361: 151-160, 2003 .

3. Kay AB: Overview of 'allergy and allergic diseases: with a view to the future'. Br Med Bull 56: 843-864, 2000.

4. Kay AB: Allergy and allergic diseases. First of two parts. N Engl J Med 344: 30-37, 2001.

5. Jin H, He R, Oyoshi M and Geha RS: Animal models of atopic dermatitis. J Invest Dermatol 129: 31-40, 2009.

6. Spergel JM and Paller AS: Atopic dermatitis and the atopic march. J Allergy Clin Immunol 112 (Suppl 6): S118-S127, 2003.

7. Turner KJ, Stewart GA, Sharp AH and Czarny D: Standardization of allergen extracts by inhibition of RAST, skin test, and chemical composition. Clin Allergy 10: 441-450, 1980.
8. Johansson SG: ImmunoCAP specific IgE test: an objective tool for research and routine allergy diagnosis. Expert Rev Mol Diagn 4: 273-279, 2004.

9. Petersen AB, Gudmann P, Milvang-Grønager P, Mørkeberg R, Bøgestrand S, Linneberg A and Johansen N: Performance evaluation of a specific IgE assay developed for the ADVIA centaur immunoassay system. Clin Biochem 37: 882-892, 2004.

10. Bae CJ, Lee JW, Bae HS, Shim SB, Jee SW, Lee SH. Lee CK, Hong JT and Hwang DY: Detection of allergenic compounds using an IL-4/luciferase/CNS-1 transgenic mice model. Toxicol Sci 120: 349-359, 2011.

11. Kwak MH, Kim JE, Hwang IS, Lee YJ, An BS, Hong JT, Lee SH and Hwang DY: Quantitative evaluation of therapeutic effect of Liriope platyphylla on phthalic anhydride-induced atopic dermatitis in IL-4/Luc/CNS-1 Tg mice. J Ethnopharmacol 148: 880-889, 2013

12. Lee JJ, Lee DS and Kim HB: Fermentation patterns of chungkookjang and Kanjang by Bacillus licheniformis B1. Korean J Microbiol 35: 296-301, 1999.

13. Nakajima N, Nozaki N, Ishihara K, Ishikawa A and Tsuji H: Analysis of isoflavone content in tempeh, a fermented soybean, and preparation of a new isoflavone-enriched tempeh. J Biosci Bioeng 100: 685-687, 2005.

14. Kwon DY, Jang JS, Lee JE, Kim YS, Shin DH and Park S: The isoflavonoid aglycone-rich fractions of Chungkookjang, fermented unsalted soybean, enhance insulin signaling and peroxisome proliferator-activated receptor-gamma activity in vitro. Biofactors 26: 245-258, 2006.

15. Su CL, Wu CJ, Chen FN, Wang BJ, Shen SR and Won SJ: Supernatant of bacterial fermented soybean induces apoptosis of human hepatocellular carcinoma Hep 3B cells via activation of caspase- 8 and mitochondria. Food Chem Toxicol 45: 303-314, 2007.

16. Kim MH, Kim SY, Ko JM, Jeong DY and Kim YS: Biological activities of cheonggukjang prepared with several soybean cultivars. Food Sci Biotechnol 21: 475-483, 2012.

17. Kwon EY, Jung KO, Moon SH and Park KY: Studies on enhancing chemopreventive effect of chungkookjangs-antimutagenic activity of chungkookjangs prepared with the different varieties of soybean and starter. J Korean Assoc Cancer Prev 7: 200-209, 2002.

18. Choi J, Kwon SH, Park KY, Yu BP, Kim ND, Jung JH and Chung HY: The anti-inflammatory action of fermented soybean products in kidney of high-fat-fed rats. J Med Food 14: 232-239, 2011.

19. Jalin AMA, Lee CK, Lee CY, Kang AR, Park CM, Cha J, Kim JH, Lee SW, Song YS, Lee JT and Kang SG: Thrombolytic activity of cheonggukjang kinase in recovery from brain damage in a rat cerebral embolic stroke model. Neural Regen Res 5: 1875-1882, 2010.

20. Ko JA, Koo SY and Park HJ: Effects of alginate microencapsulation on the fibrinolytic activity of fermented soybean paste (cheonggukjang) extract. Food Chem 111: 921-924, 2008.

21. Matsuda A, Tanaka A, Pan W, Okamoto N, Oida K, Kingyo N, Amagai Y, Xia Y, Jang H, Nishikawa S, Kajiwara N, Ahn G, Ohmori K and Matsuda H: Supplementation of the fermented soy product ImmuBalance ${ }^{\mathrm{TM}}$ effectively reduces itching behavior of atopic NC/Tnd mice. J Dermatol Sci 67: 130-139, 2012.

22. Jang SN, Kim KL, Yun MY and Kang SM: The effect of $\gamma$-PGA on NC/Nga mice, a mouse model for mite antigen-induced atopic dermatitis. Korean J Microbiol Biotechnol 38: 53-63, 2010 (In Korean).

23. Choi YH, Lim H, Heo MY, Kwon DY and Kim HP: Antiinflammatory activity of the ethanol extract of chungkukjang, Korean fermented bean: 5-lipoxygenase inhibition. J Med Food 11: 539-543, 2008.

24. Hwang IS, Kim JE, Lee YJ, Kwak MH, Lee HG, Kim HS, Lee HS and Hwang DY: Growth sensitivity in the epiphyseal growth plate, liver and muscle of SD rats is significantly enhanced by treatment with a fermented soybean product (cheonggukjang) through stimulation of growth hormone secretion. Mol Med Rep 9: 166-172, 2014.

25. Lee YJ, Kim JE, Kwak MH, Go J, Son HJ, Kim DS and Hwang DY: In vitro and in vivo study of effects of fermented soybean product (chungkookjang) on NGF secretion ability and NGF receptor signaling pathway. Lab Anim Res 29: 113-126, 2013.

26. Zhang $\mathrm{G}$ and Brown AW: The rapid determination of gamma-aminobutyric acid. Phytochemistry 44: 1007-1009, 1997. 
27. Kim JE, Lee YK, Nam SH, Choi SI, Goo JS, Jang MJ, Lee HS, Son HJ, Lee CY and Hwang DY: The symptoms of atopic dermatitis in $\mathrm{NC} / \mathrm{Nga}$ mice were significantly relieved by the water extract of Liriope platyphylla. Lab Anim Res 26: 377-384, 2010.

28. Stahlmann R, Wegner M, Riecke K, Kruse M and Platzek T: Sensitising potential of four textile dyes and some of their metabolites in a modified local lymph node assay. Toxicology 219: 113-123, 2006.

29. Bae CJ, Shim SB, Jee SW, Lee SH, Kim MR, Lee JW, Lee CK and Hwang DY: IL-6, VEGF, KC and RANTES are a major cause of a high irritant dermatitis to phthalic anhydride in C57BL/6 inbred mice. Allergol Int 59: 389-397, 2010.

30. Prussin C and Metcalfe DD: 4. IgE, mast cells, basophils, and eosinophils. J Allergy Clin Immunol 111 (Suppl 2): S486-S494, 2003.

31. Spergel JM, Mizoguchi E, Brewer JP, Martin TR, Bhan AK and Geha RS: Epicutaneous sensitization with protein antigen induces localized allergic dermatitis and hyperresponsiveness to methacholine after single exposure to aerosolized antigen in mice. J Clin Invest 101: 1614-1622, 1998.

32. Kimura M, Tsuruta S and Yoshida T: Correlation of house dust mite-specific lymphocyte proliferation with IL-5 production, eosinophilia, and the severity of symptoms in infants with atopic dermatitis. J Allergy Clin Immunol 101: 84-89, 1998.

33. Man MQ, Hatano Y, Lee SH, Man M, Chang S, Feingold KR, Leung DY, Holleran W, Uchida Y and Elias PM: Characterization of a hapten-induced, murine model with multiple features of atopic dermatitis: structural, immunologic, and biochemical changes following single versus multiple oxazolone challenges. J Invest Dermatol 128: 79-86, 2008.

34. Laouini D, Kawamoto S, Yalcindag A, Bryce P, Mizoguchi E, Oettgen $\mathrm{H}$ and Geha RS: Epicutaneous sensitization with superantigen induces allergic skin inflammation. J Allergy Clin Immunol 112: 981-987, 2003.

35. Chan LS, Robinson $\mathrm{N}$ and Xu L: Expression of interleukin-4 in the epidermis of transgenic mice results in a pruritic inflammatory skin disease: an experimental animal model to study atopic dermatitis. J Invest Dermatol 117: 977-983, 2001.

36. Dillon SR, Sprecher C, Hammond A, et al: Interleukin 31, a cytokine produced by activated $\mathrm{T}$ cells, induces dermatitis in mice. Nat Immunol 5: 752-760, 2004.

37. Soumelis V, Reche PA, Kanzler H, et al: Human epithelial cells trigger dendritic cell mediated allergic inflammation by producing TSLP. Nat Immunol 3: 673-680, 2002.
38. Kim E, Lee JE, Namkung JH, Park JH, Kim S, Shin ES, Cho EY and Yang JM: Association of the single-nucleotide polymorphism and haplotype of the interleukin 18 gene with atopic dermatitis in Koreans. Clin Exp Allergy 37: 865-871, 2007.

39. Weih F, Warr G, Yang H and Bravo R: Multifocal defects in immune responses in RelB-deficient mice. J Immunol 158: 5211-5218, 1997.

40. Tsukuba T, Okamoto K, Okamoto Y, Yanagawa M, Kohmura K, Yasuda Y, Uchi H, Nakahara T, Furue M, Nakayama K, Kadowaki T, Yamamoto K and Nakayama KI: Association of cathepsin E deficiency with development of atopic dermatitis. J Biochem 134: 893-902, 2003.

41. Watanabe O, Natori K, Tamari M, Shiomoto Y, Kubo S and Nakamura Y: Significantly elevated expression of PF4 (platelet factor 4) and eotaxin in the NOA mouse, a model for atopic dermatitis. J Hum Genet 44: 173-176, 1999.

42. Hikita I, Yoshioka T, Mizoguchi T, Tsukahara K, Tsuru K, Nagai H, Hirasawa T, Tsuruta Y, Suzuki R, Ichihashi M and Horikawa T: Characterization of dermatitis arising spontaneously in DS-Nh mice maintained under conventional conditions: another possible model for atopic dermatitis. J Dermatol Sci 30: 142-153, 2002.

43. Kim JE, Hwang IS, Goo JS, Nam SH, Choi SI, Lee HR, Lee YJ, Kim YH, Park SJ, Kim NS, Choi YH and Hwang DY: LP9M80-H isolated from Liriope platyphylla could help alleviate diabetic symptoms via the regulation of glucose and lipid concentration. J Life Sci 22: 634-641, 2012.

44. Kawakami T, Ando T, Kimura M, Wilson BS and Kawakami Y: Mast cells in atopic dermatitis. Curr Opin Immunol 21: 666-678, 2009

45. Galli SJ: Mast cells and basophils. Curr Opin Hematol 7: 32-39, 2000.

46. Gao XK, Nakamura N, Fuseda K, Tanaka H, Inagaki N and Nagai H: Establishment of allergic dermatitis in NC/Nga mice as a model for severe atopic dermatitis. Biol Pharm Bull 27: 1376-1381, 2004.

47. Dearman RJ, Skinner RA, Humphreys NE and Kimber I: Methods for the identification of chemical respiratory allergens in rodents: comparisons of cytokine profiling with induced changes in serum IgE. J Appl Toxicol 23: 199-207, 2003. 